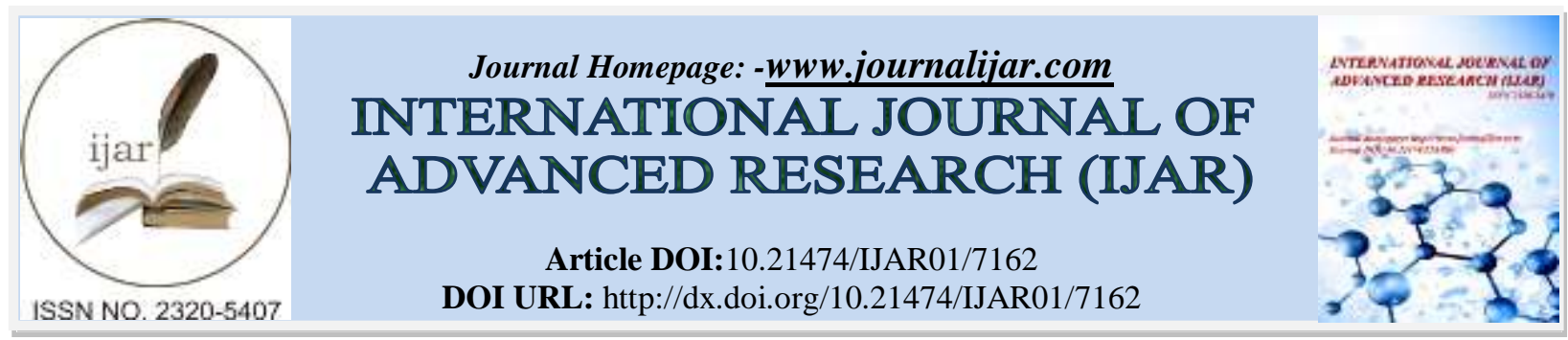

RESEARCH ARTICLE

\title{
LAPAROSCOPIC TRANS-ABDOMINAL PRE-PERITONEAL MESH HERNIOPLASTY FOR INGUINAL HERNIAS: A TERTIARY CARE INSTITUTE EXPERIENCE.
}

Zahid Mohd Rather, Mohd Nazrull Islam, Zubair Gul Lone, Aabid Rasool Bhat and Nighat Ara Majid.

\section{Manuscript Info}

..........................

Manuscript History

Received: 21 March 2018

Final Accepted: 23 April 2018

Published: May 2018

Keywords:-

Inguinal Hernias, Laparoscopy, Transabdominal Preperitoneal Hernia Repair.

\section{Abstract}

Introduction: In the era of minimal invasive surgery, hernia repair has seen a paradigm shift from open to laparoscopic technique. Laparoscopic hernioplasty is the latest technique with several advantages over open procedures like reduced post operative pain, shorter recovery period. However the steeper learning curve and cost of the procedure have been cited as limiting factor.

Aims and objectives: To study the outcome of laparoscopic transabdominal pre-peritoneal mesh hernioplasty for inguinal hernias in terms of operative time, complications, Hospital stay and recurrence.

Material and methods: This study was carried out from December 2011 to January2017. Case records of 112 patients that underwent trans-abdominal pre-peritoneal (TAPP) by a single surgical team were followed prospectively for a period of 1 year. All patients, above 18 years of age with uncomplicated inguinal hernia were included in the study. Complicated hernias, patients unfit for general anesthesia, patients with previous lower abdominal or pelvic surgery and patients unwilling to take part in study were excluded from the study. Data regarding, operative time, complications, chronic post operative pain, hospital stay and recurrence were recorded and evaluated.

Results: 112 patients presenting with uncomplicated inguinal hernias were operated over a period of five years. The age of the patients ranges from 15-70 years. There were $106(94.64 \%)$ male patients and 6 (5.35\%) female patients. Mean operative time was 55 minutes (range 40-110 minutes).The complications that occurred, were bleeding $1(0.89 \%)$, conversion to open $1(0.89 \%)$, seroma $4(3.57 \%)$, urinary retention $4(3.57 \%)$, chronic pain $3(2.67 \%)$ and recurrence $3(2.67 \%)$. No incidence of bowel injury, bladder injury, spermatic cord injury, scrotal hematoma, mesh infection and port site infection has been reported. Average Hospital stay was 1.2 days (1-3). 97.33\% were satisfied with their repair and returned to work after with a median of 15.1 days (12-21 days).

\section{Conclusion:}

We concluded that TAPP is an effective and safe procedure with low prevalence of chronic pain, that was generally of a mild, infrequent nature, faster convalesce and return to productive activity with fewer complications and a recurrence rate as low as that of an open mesh repair. However operative time is prolonged which decreases with experience. Learning curve is not as steep as claimed, and considering 
advantages, the cost of the procedure should not be a limiting factor even in developing countries.

Copy Right, IJAR, 2018,. All rights reserved.

\section{Introduction:-}

The hernia repair is one of the most common surgical procedures worldwide; at Least 2000000 hernia repair procedures are annually performed [1]. The standard method for inguinal hernia repair has changed until the introduction of mesh and minimal access laparoscopic technique. The concept of inguinal hernia repair underwent evolution from Bassini's repair to Lichtenstein tension-free repair with the introduction of polyethylene mesh [2]. Mesh placement can be achieved by both open and laparoscopic techniques [3]. Laparoscopic repair was first reported by Ger in 1990[4]. There are three techniques of laparoscopic hernia repair, namely trans-abdominal preperitoneal repair (TAPP), totally extra-peritoneal repair (TEP), and intra-peritoneal onlay mesh repair (IPOM).Laparoscopic hernia repair is technically more demanding than its open counterpart and there is evidence of a long learning curve [5]. Laparoscopic inguinal hernia repair has benefit of less postoperative pain, reduced recovery time, easier repair of a recurrent hernia, concurrent treatment of bilateral hernias, earlier return to daily activities and work and improved cosmesis [6,7]. Recurrence rate may be lower in TAPP as compared to open technique due to pre-peritoneal tension free mesh placement [8, 9]. A number of studies have shown laparoscopic repair of inguinal hernias to have advantages over conventional repair [10-12]. The laparoscopic TAPP works on Pascal's law of hydraulics.

\section{Aims and Objective:-}

To study the outcome of laparoscopic trans-abdominal pre-peritoneal mesh hernioplasty for inguinal hernias in terms of operative time, Complications,Hospital stay and recurrence.

\section{Material and Methods:-}

The study was under taken in the Post Graduate Department of General and Minimal Access Surgery, Govt. Medical College Srinagar from December 2011 to January 2017. Case records of 112 patients that underwent TAPP by a single surgical team were followed prospectively for a period of 1 year. All patients, above 18 years of age with uncomplicated inguinal hernia were included in the study. Complicated hernias, patients unfit for general anesthesia, patients with previous lower abdominal or pelvic surgery and patients unwilling to take part in study were excluded from the study. The following data was collected prospectively: age, sex, operative time, post operative pain, intraoperative complications, Post-operative complications, hospital stay and recurrence. All the patients enrolled for the study were evaluated by detailed history, thorough general physical examination, and focused systemic examination. Informed consent was taken before surgery in the language the patients understood. The patient was explained the various available modalities of treatment with their potential benefits and material risks and also explained about the possibility of conversion to open surgery, if there are technical difficulties or in the interest of the patients' safety and well-being. The patient was kept fasting overnight. Single dose of Ceftriaxone (1 g) was used as antibiotic prophylaxis half an hour before surgery

\section{Operative Procedure:-}

All patients were asked to void before the start of the procedure. General anesthesia with Endo-tracheal intubation was preferred. The surgeon stood on the contra-lateral side of the hernia. The head end of the table was slanted down to $10^{\circ}$ for the establishment of pneumo-peritoneum by closed technique and a monitor with high definition laparoscopic equipment were placed to the foot end of the table; the monitor were located on the side of hernias. Trocars were placed under establishing the carbon dioxide pneumo-peritoneum using the Verres needle. A 10mm optical port was placed through the supra-umbilical incision. Two $5 \mathrm{~mm}$ ports were placed as working ports for the right and left hand of the surgeon, one on each side, at the level of the umbilicus in the mid-clavicularline. The operating trocars were inserted underlaparoscopic view control. The aim of the laparoscopic exploration was identifying the anatomical landmarks and the site and type of hernia (direct or indirect) established by the position of the defect with respect to the inferior epigastric vessels and cord structures. The Trendelenburg tilt was increased to $30-45^{\circ}$. The two dangerous triangles, 'vascular triangle and pain triangle' has to be identified. Contents of the hernial sac, if any, were reduced with the help of atraumatic bowel forceps. The pre-peritoneal dissection was started at the lateral part of the internal inguinal ring and continued medially and caudally at the level of Retzius until the pubis is well exposed. Then, the hernia sac dissection was performed using traction contra-traction maneuvers and fine coagulation and obliterated by vicryl Endo-loop. To avoid the injuries of the ductus deferens and spermatic vessels, 
the sac dissection always started anteriorly. The pre-peritoneal dissection ends when the anatomic landmarks, inferior epigastric vessels, urinary bladder, pubis and Cooper's ligament, Gimbernat's ligament and medial part of ilio-pubic tract, external iliac vessels, corona mortis vein, ductus deferens and spermatic vessels, internal inguinal ring are well exposed. A polypropylene mesh of $15 \mathrm{~cm} \times 12 \mathrm{~cm}$ was used for the repair. The mesh was introduced into the operating field through the $10 \mathrm{~mm}$ umbilical port by removing the telescope, after which the telescope was reinserted. The first staple was at the level of iliac spine $(2 \mathrm{~cm}$ above it); then, the mesh was fixed on the upper and internal edge, as well as at the level of pubis and pectineal ligament. The mesh hasn't to be stapled at the level of dangerous triangles and epigastric vessels. After placement of the mesh, the peritoneal flap was closed over the mesh to prevent bowel and omental adhesions; this was done with sutures. The carbon dioxide gas was evacuated to empty the abdominal cavity and scrotum. The ports were removed after lifting the anterior abdominal wall. The sheath of the $10 \mathrm{~mm}$ port was closed. Skin incisions were closed with simple sutures. In cases of bilateral hernias, we used two separate pieces of mesh that were secured together in the midline. The mesh was placed in the first hernia but the peritoneum was not closed until the other side was completed. Figure 1-6.

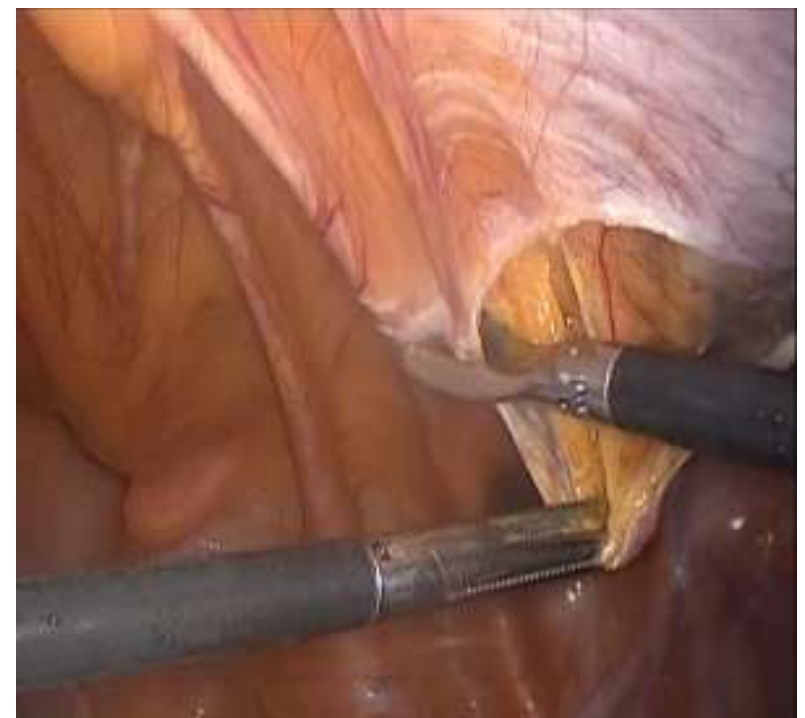

Figure 1:- Showing dissection at $2 \mathrm{~cm}$ superolateral pouch to deep inguinal ring

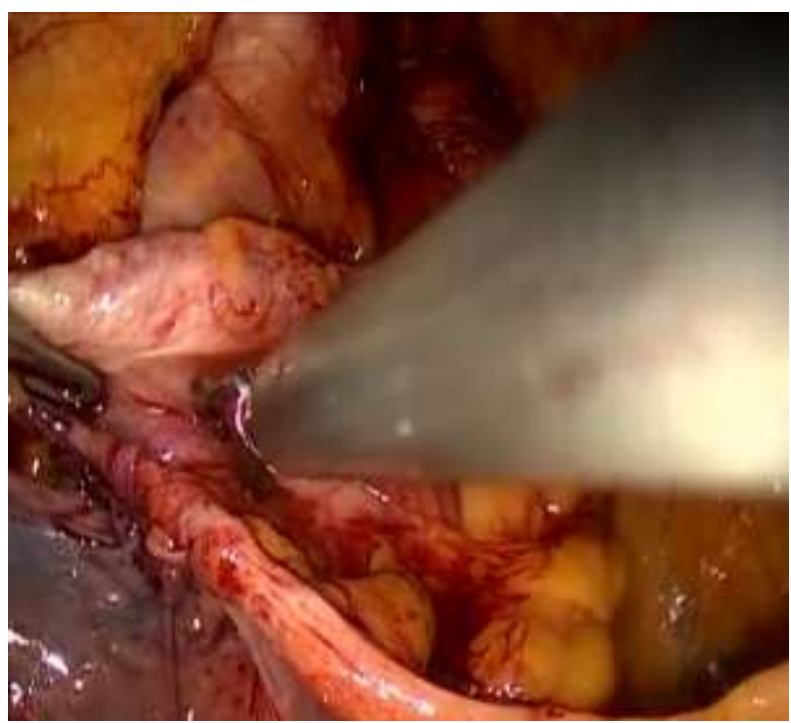

Figure 3:- Showing separation of sac from cord structures.

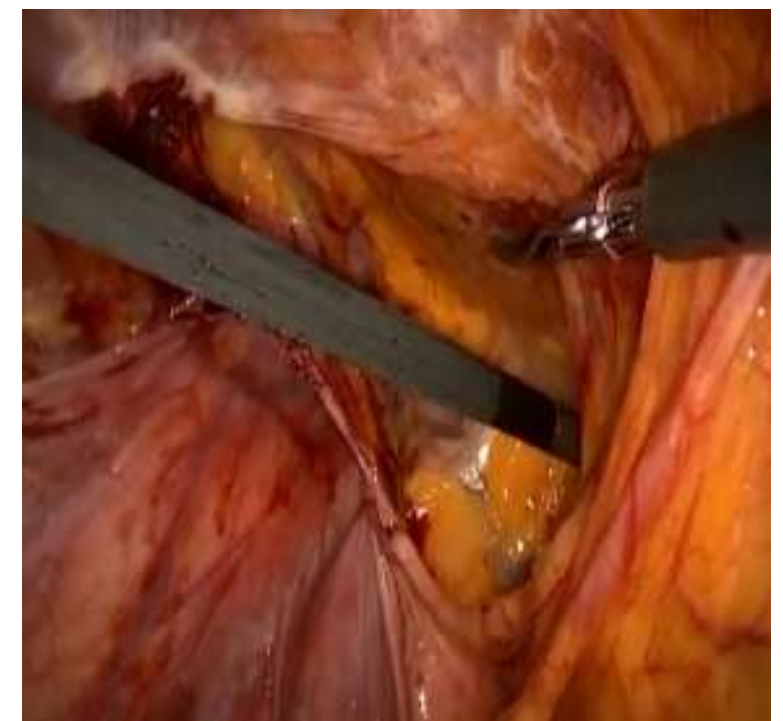

Figure 2:- Development of lateral pre-peritoneal

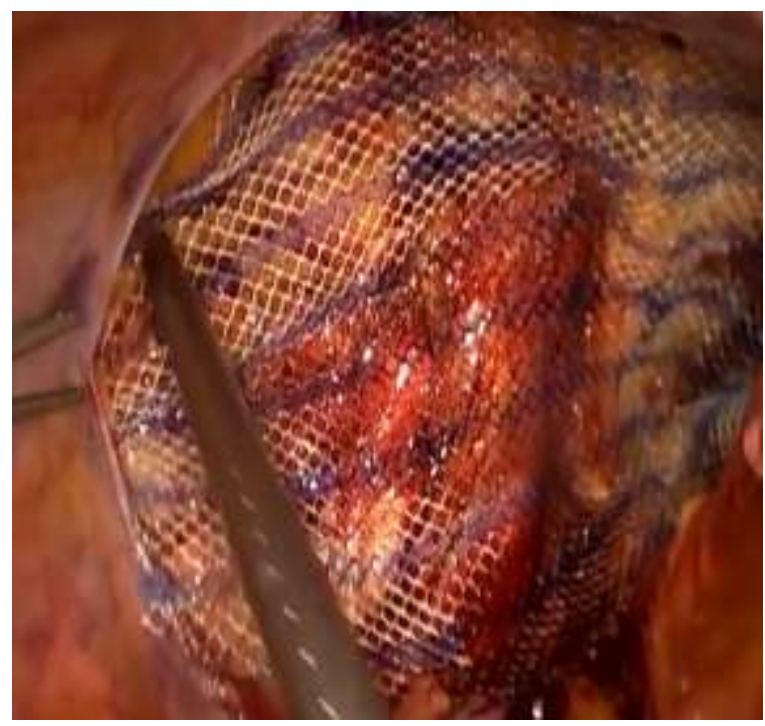

Figure 4:- Showing display of prolene mesh. 


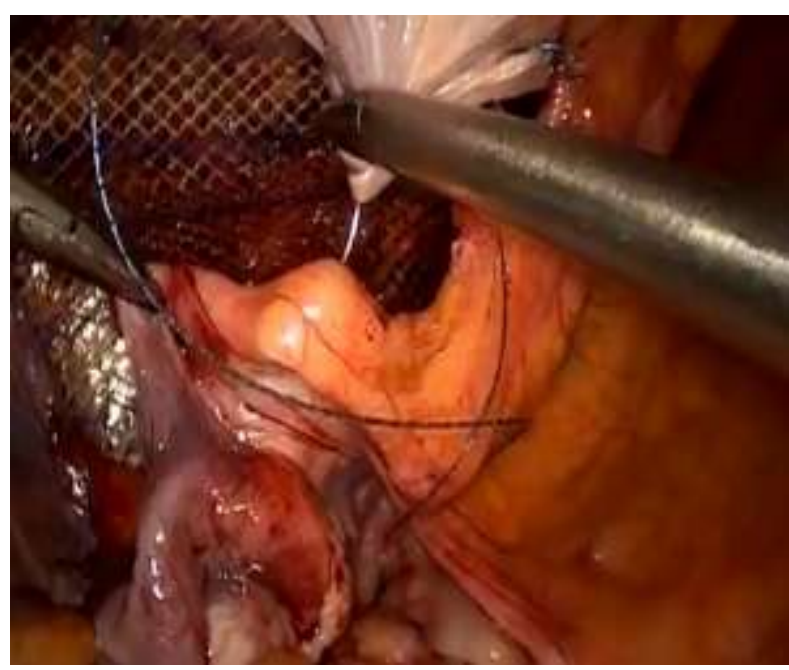

Figure 5:- Showing V-lock used for repair of peritoneum.

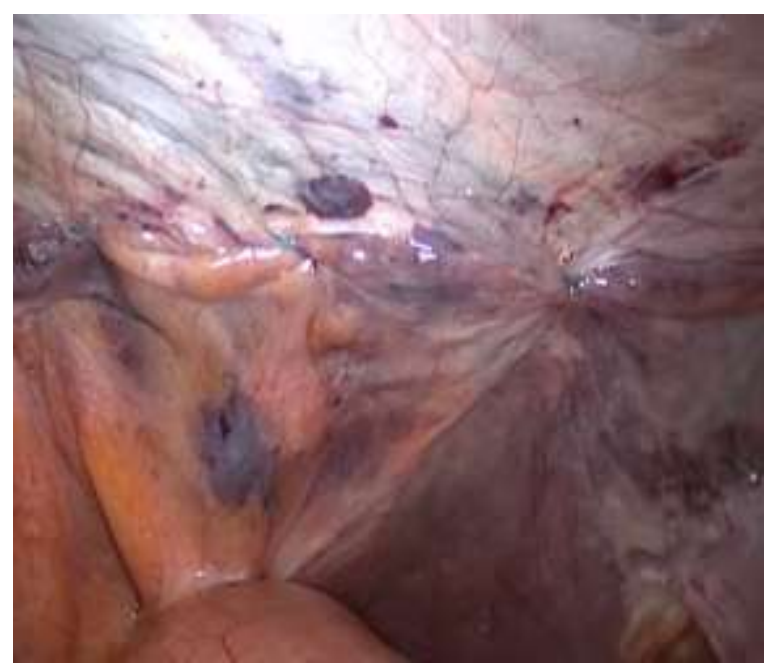

Figure 6:- showing complete repair of peritomium

\section{Postoperative Care:-}

1. Orals were started as soon as the patients started to tolerate them.

2. A second dose of intravenous antibiotics was given 12 hours after surgery.

3. Analgesics were given on demand only.

Monitoring of the patient for Pulse, Blood pressure, Temperature, Respiratory rate, urine output (color and quantity), and appearance of bowel sounds and passage of flatus was done. The patients were typically discharged home on 1 st postoperative day on tablet Cefuroxime $500 \mathrm{mg}$ BD and tablet diclofenac $25 \mathrm{mg}$ BD for 3 days orally postoperatively. The patients were instructed to avoid heavy lifting for 3 months postoperatively. Patients were advised to follow-up in OPD at 1 week, 4 weeks, 6 months and 1year

\section{Results:-}

The age of the patients enrolled in the study group ranged from $15-70$ years and majority of them 39 (34.82\%) were in the age range of 46-60 years. There were $106(94.64 \%)$ male patients and $6(5.35 \%)$ female patients [Table1].

\begin{tabular}{|l|l|l|}
\hline Table 1:-Age Distribution(N =112) & Percentage \\
\hline Age in Years & Number of Patients & 24.10 \\
\hline $15-30$ & 27 & 32.12 \\
\hline $31-45$ & 36 & 34.82 \\
\hline $46-60$ & 39 & 8.92 \\
\hline $60-70$ & 10 & \\
\hline Male/Female & $106 / 6$ & \\
\hline
\end{tabular}

In our study 61 patients presented with right sided inguinal hernia, 43 on the left sided inguinal hernia and 8 patients presented with bilateral inguinal hernia.63 (56.52\%) patients presented with indirect inguinal hernia and 49 $(43.75 \%)$ patients with direct inguinal hernia [Table 2].

\begin{tabular}{|l|l|l|l|l|l|}
\hline \multicolumn{2}{|l|}{ Table 2:- Type of hernia } \\
\hline Sr. No & $\begin{array}{l}\text { Type } \\
\text { Hernia }\end{array}$ & $\begin{array}{l}\text { Right side } \\
(\mathrm{n}=61)\end{array}$ & $\begin{array}{l}\text { Left side } \\
(\mathrm{n}=43)\end{array}$ & $\begin{array}{l}\text { Bilateral } \\
(\mathrm{n}=8)\end{array}$ & $\begin{array}{l}\text { Total } \\
(\mathrm{N}=112)\end{array}$ \\
\hline 1 & Indirect & 34 & 24 & 5 & 63 \\
& & $(30.35 \%)$ & $(21.42 \%)$ & $(4.46 \%)$ & $(56.52 \%)$ \\
\hline 2 & Direct & 27 & 19 & 3 & 49 \\
$(24.10 \%)$ & $(16.96 \%)$ & $(2.67 \%)$ & $43.75 \%$ \\
\hline
\end{tabular}


Mean operative time was 55 minutes (range 40-110 minutes). The complications that occurred, were bleeding $1(0.89 \%)$, conversion to open $1(0.89 \%)$, seroma $4(3.57 \%)$, urinary retention $4(3.57 \%)$, chronic pain $3(2.67 \%)$ and recurrence $3(2.67 \%)$. No incidence of bowel injury, bladder injury, spermatic cord injury, scrotal hematoma, mesh infection and port site infection has been reported. Average Hospital stay was 1.2 days (1-3) [Table 3]. 97.33\% were satisfied with their repair and returned to work after with a median of 15.1 days (12-21 days). Patients required less analgesia at home and returned to their normal lifestyle more rapidly. During follow-up at one month there was no recurrence but at 6 months follow up recurrence in 2 patients and at 1 year follow up recurrence in 1 patient.

Table 3:-Intra-operative and post operative data

\begin{tabular}{|l|l|}
\hline Variable & Result \\
\hline Mean Operative Time ,minutes & $55(45-110)$ \\
\hline Bleeding & $1(0.89 \%)$ \\
\hline Bowel Injury & $0(0.00 \%)$ \\
\hline Bladder Injury & $0(0.00 \%)$ \\
\hline Conversion to open & $1(0.89 \%)$ \\
\hline Spermatic cord Injury & $0(0.00 \%)$ \\
\hline Seroma & $4(3.57 \%)$ \\
\hline Scrotal Hematoma & $0(0.00 \%)$ \\
\hline Urinary Retention & $4(3.57 \%)$ \\
\hline Chronic Pain & $3(2.67 \%)$ \\
\hline Mesh Infection & $0(0.00 \%)$ \\
\hline Port Site Infection & $0(0.00 \%)$ \\
\hline Average Hospital Stay, Days & $1.2(1-3)$ \\
\hline Recurrence & $3(2.67 \%)$ \\
\hline Follow up, Months & $6(6-12)$ \\
\hline
\end{tabular}

\section{Discussion:-}

The concept of inguinal hernia repair underwent evolution from Bassini's repair to Lichtenstein tension-free repair with the introduction of polyethylene mesh [2].After the advent of minimally invasive surgery (MIS), open surgery has been gradually replaced by laparoscopic surgery.

In our study, $39(34.82 \%)$ patients were in age group of 46-60 years. There were only $6(5.35 \%)$ female patients in the study, rest 106 (94.64\%) were males. Similar results were found in the study conducted by Aymanet al. [13], Ghaniet al. [14].Majority of patients 61 (54.46\%), presented with right side inguinal hernia, 43(38.39\%) with left side inguinal hernia and $8(7.14 \%)$ patients present with bilateral hernia, so the total hernia repaired were 120. Most common type of hernia seen in our study was unilateral indirect inguinal hernia 56.52\% (63/112). These findings are consistent with the various other studies from Nepal, Korea and India [15-17]. We also evaluated the mean operative time for the procedure; it was 55 minutes (range 45-110 minutes). The operative time decreased with experience. The results were comparable to the study conducted by Zeineldin et al [18]( mean operative time $43 \pm 11.3$ minutes ).The mean operative duration in TAAP repair was $60.13 \pm 14.76$ minutes in the study conducted by Ghaniet al. [14].

Complications that occurred in our study were bleeding $1(0.89 \%)$, due to adhesions and injury to inferior epigastric artery, this patient was managed by converted in to open surgery. Bleeding can occur during any operation, but it is especially troublesome during laparoscopic hernioplasty. Because of limited access to the bleeding site and high flow rates of those vessels most likely to be injured, bleeding must be controlled quickly or avoided completely. The location of the inferior epigastric vessels may vary, and injury to these vessels is the most common cause of bleeding. Seroma was present in $4(3.57 \%)$ patients who were managed by conservatively without aspiration or exploration. Our results were similar to the study conducted by Zeineldin et al [18] who found seroma in 6\% of patients. The chronic Postoperative pain was seen in $3(2.67 \%)$ patients and was less compared to the study conducted by Sondenaaet al. [19] that reported postoperative pain in $10 \%$ of patients and was easily controlled by oral analgesics. 
Urinary retention was presented in $4(3.57 \%)$ of patients, which were managed by outpatient basis. Urinary retention is seen in approximately $2 \%$ of patients after open or laparoscopic hernioplasty and is probably related to the group of patients undergoing the procedure and the technique itself [20].

Average hospital stay in our study group was 1.2 days (range 1-3 days) and returned to routine work in median of 15.1 days (range 12-21 days). Which was comparable to the study conducted by Aymanet al. [13], in their study the mean time to return to work after TAAP was 14.4 days. Liem et al [21] reported that patients following laparoscopic inguinal hernia repair resumed normal daily activity 4 days earlier and returned to work 7 days earlier than open repair. Patients with laparoscopic repair resumed athletic activities 12 days earlier than those who had open repair. Recurrence is the most important indicator of the success of hernia procedures which may occur in $15 \%$ of the cases or more. The frequency of hernia recurrence depends on many factors including type of hernia repair, the comorbidities of the patient, and the experience of the operating surgeon itself. In our study recurrence was present in $3(2.67 \%)$ patients, most of them occurred during first 6 months. McCormack K et al [22], reported 86 recurrences among 3138 patients i.e (2.7\%) who underwent Laparoscopic repair which was comparable to our study. No incidence bowel injury, bladder injury, spermatic cord injury, scrotal haematoma, meshes infection and port site infection has been reported in our study so far.

Laparoscopic procedure is technically more demanding than the open inguinal operation and it must be performed under general anesthesia. The cost of instruments, mesh and clip appliers are important drawbacks. However, the excellent results, a low complication rate, nearly painless postoperative course, short hospital stay, are very encouraging. Laparoscopic approach has shown clear advantages regarding less chronic postoperative pain and numbness, fast return to normal activities, and a decrease in the incidence of wound infection and hematoma, it should be considered an appropriate approach for inguinal hernia surgery.

\section{Conclusion:-}

We concluded that TAPP is an effective and safe procedure with low prevalence of chronic pain, that was generally of a mild, infrequent nature, faster convalesce and return to productive activity with fewer complications and a recurrence rate as low as that of an open mesh repair. However operative time is prolonged which decreases with experience. Learning curve is not as steep as claimed, and considering advantages, the cost of the procedure should not be a limiting factor even in developing countries.

\section{Reference:-}

1. Leroy J. Transabdominal preperitoneal approach (TAPP). Epublication: WeBSurg.com, Mar 2001;1(3). URL: http://www.websurg.com/ref/doi-ot02en194.htm

2. Patino JF. A history of the treatment of hernia. In. Nyhus LM. Condon RE, editor.Hernia. 4th ed. Philadelphia (PA). JB Lippincott company; 1995. pp . 3-15.

3. Horeyseck G, Roland F, Rolfes N. 'Tension free'repair of inguinal hernia. Laparoscopic (TAPP) versus open (Lichtenstein) repair. Chirurg 1996 0ct; 67(10):1036-1040.

4. Haller JO,KassnerG,Ostrowitz A, Kottmeler K, Perfschuk LP. Pilomatrixoma (calcifying epithelioma of Malherbe): radiographic features. Radiology. 1977;123:151-3.[Link]

5. Wright, D. The Learning Curve for Laparoscopic Hernia Repair. Seminars in Laparoscopic Surgery (1998);5, 227- 232. http://dx.doi.org/10.1177/155335069800500405

6. Filipi CJ, Fitzgibbons RJ,Jr., Salerno GM, Hart RO. Laparoscopic herniorrhaphy. SurgClin North Am. 1992;72:1109-24.[Link]

7. Felix EL, Michas C. Double-buttress laparoscopic herniorrhaphy. J Laparoendosc Surg. 1993;3:1-8.[Link]

8. Arregui ME, Navarrete J, Davis CJ, Castro D, Nagan RF. Laparoscopic inguinal herniorrhaphy. Techniques and controversies. SurgClin North Am. 1993;73: 513-27. [Link]

9. Spaw AT, Ennis BW, Spaw LP. Laparoscopic hernia repair: the anatomic basis. J Laparoendosc Surg. 1991;1: 269-77.[Link]

10. Memon, M.A., Cooper, N.J., Memon, B., Memon, M.I. and Abrams, K.R. Metaanalysis of Randomized Clinical Trials Comparing Open and Laparoscopic Inguinal Hernia Repair. British Journal of Surgery, (2003) ;90, 14791492. http://dx.doi.org/10.1002/bjs.4301

11. McCormack, K., Scott, N., Go, P.M., Ross, S.J. and Grant, A. Collaboration the EU Hernia Trialists: Laparoscopic Techniques versus Open Techniques for Inguinal Hernia Repair. Cochrane Database of Systematic Reviews, 2003, CD001785. 
12. Takata, M.C. and Duh, Q.Y. Laparoscopic Inguinal Hernia Repair. Surgical Clinics of North America, (2008) ;88, 157-178. http://dx.doi.org/10.1016/j.suc.2007.10.005

13. Elwan, A.M., Abomera, M.A., Abo Al Makarem, M.A., and AbdAlhamed, H. (2013) Mohammedain: LaparoscopicTransabdominalPreperitoneal Repair versus Open Preperitoneal Mesh Repair for Inguinal Hernia. Journal of the Arab Society for Medical Research, 8, 38-42.

14. Ghani, A., Khalil, J., Khan, M.I. and Khan, H. Laparoscopic TransabdominalPreperitoneal versus Lichtenstein Tension Free Repair for Inguinal Hernia. Pakistan Journal of Surgery, (2012) ;28, 6-11.

15. Shakya VC, Sood S, Bhattarai BK, Agarwal CS, Adhikary S. Laparoscopic inguinal hernia repair: a prospective evaluation at Eastern Nepal. Pan Med J. 2014;17: 241. [Link]

16. Choi YY, Han SW, Bae SH, Kim SY, Hur KY, Kang GH. Comparison of the outcomes between laparoscopic totally extraperitoneal repair and prolene hernia system for inguinal hernia; review of one surgeon's experience. Transabdominal Pre-peritoneal Mesh Repair versus Lichtenstein's HernioplastyJNHRC Vol. 15 No. 2 Issue 36 May - Aug 2017 Journal of the Korean Surgical Society. 2012 Jan 1;82(1):40-4. [Link]

17. Beeraka C, Surapaneni S, Raavi R. Repair of a primary inguinal hernia by using a polypropylene mesh: a tension free Lichtenstein repair in rural Andhra Pradesh. ClinDiagn Res. 2012;6: 261-3.

18. Zeineldin, A. Transabdominal (TAPP) versus Total Extraperitoneal (TEP) Laparoscopic Inguinal Hernia Repair: A Prospective Comparative Study. Menoufiya Medical Journal, (2008);21.

19. Sondenaa, K., Nesvik, I., Breivik, K. and Korner, H. Long-Term Follow up of 1059 Consecutive Primary and Recurrent Inguinal Hernias in a Teaching Hospital. European Journal of Surgery, (2001) ;67, 125 -129.

20. Miguel PR, Reusch M, DaRosa ALM, Carlos JR. Laparoscopic hernia repair -complications.JSLS.1998: 2:3540.

21. Liem MS, van Duyn EB, van der Graaf Y, van vroonhovenTJ;Coala trial Group. Recurrences after conventional anterior and laparoscopic inguinal hernia repair: a randomized comparision. Ann Surg 2003; 237(1): 136-141.

22. McCormack K, Scott NW, Go PM, Ross S, Grant AM, EU Hernia, Trialists Collaboration. Laparoscopic techniques versus open techniques for inguinal hernia repair. Cochrane Database SystRew 2003;1: CD001785. 